\title{
Théroigne de Méricourt y Olympe de Gouges. Lo que de ellas dicen sus retratos
}

\author{
Rosalía Torrent Esclapés \\ Universitat Jaume I \\ torrent@uji.es
}

RESUMEN: Dos mujeres, Théroigne de Méricourt y Olympe de Gouges, se constituyen como figuras de referencia durante la Revolución Francesa. Contrariamente a lo que se piensa, estas mujeres (y otras revolucionarias) fueron objeto de diversos estudios durante los siglos XIX y XX, aunque muchas veces partiendo de interpretaciones sesgadas y obstaculizadas por prejuicios de género. Los grabados y retratos que se les dedicaron -y conservamos- nos ayudan a situarlas en el contexto del que formaron parte. A la vez, son susceptibles de diversas interpretaciones y análisis, tanto desde un punto de vista técnico y estilístico como iconográfico. Buena parte de estas representaciones no resultan muy distantes de las que se llevaban a cabo con otros modelos más convencionales; otras abren nuevas perspectivas. Todas, junto con los poemas, escritos y apostillas que les dedicaron, nos sirven para adentrarnos en su historia.

PALABRAS CLAVE: Arte y mujeres; Théroigne de Méricourt; Olympe de Gouges; Revolución Francesa; Autorretrato; Retratos femeninos.

\section{Théroigne de Méricourt and Olympe de Gouges. What their Portraits Tell Us}

ABSTRACT: Two women, Théroigne de Méricourt and Olympe de Gouges, are leading figures in the context of the French Revolution. Contrary to what is believed, these women (and other revolutionary figures) were the subjects of various studies during the 19th and 20th centuries, although these were often based on biased interpretations hampered by gender-based prejudices. Engravings and portraits that were made of them -and that have been preserved- help us to place them in the context to which they belonged. At the same time, they are susceptible to different interpretations and analyses, both stylistic and iconographic. Many of these representations are not so different to those developed with other more conventional models; others open up new perspectives. All of them, together with poems, writings and comments devoted to them, help us to delve into their story.

KEYWORDS: Art and Women; Théroigne de Méricourt; Olympe de Gouges; French Revolution; Self-Portrait; Female Portraits.

Recibido: 19 de diciembre de 2017 / Aceptado: 27 de abril de 2018.

Todos conocemos el cuadro de Delacroix La libertad guiando al pueblo. Forma parte de esas imágenes alegóricas que representan a la libertad como una mujer, la gran madre que capitanea el movimiento social que guía al pueblo en su liberación. El cuadro narra los acontecimientos de 1830, cuando los revolucionarios liberales logran derrocar a Carlos X provocando la coronación de Luis Felipe de Orleans. La mujer que dirige el conjunto, con la bandera tricolor y rifle en mano, está acompañada por un burgués con sombrero de copa, un chico con dos pistolas, un grupo de ciudadanos que remedan a los sans-culottes y dos soldados muertos. Ella es el elemento de unión de los burgueses con el pueblo llano e incluso con esa parte del ejército que se pone del lado de los revolucionarios y que muere junto a ellos.

Cómo citar este artículo: TORRENT ESCLAPÉS, Rosalía: «Théroigne de Méricourt y Olympe de Gouges. Lo que de ellas dicen sus retratos», Boletín de Arte-UMA, n. 39 , Departamento de Historia del Arte, Universidad de Málaga, 2018, pp. 233-243, ISSN: 0211-8483, DOI: http://dx.doi.org/10.24310/BoLArte.2018.v0i39.3361 
Una mujer se convierte en el símbolo de la República Francesa. Pero este cuadro muestra una evidente paradoja: la mujer es un emblema de libertad, pero había quedado excluida de la nueva organización política inaugurada por la Revolución de 1789. En aquel año y hasta la temprana fecha de 1793 (cuando les fueron arrebatados sus incipientes derechos tras la supresión de las organizaciones femeninas), muchas mujeres se implicaron claramente en la vida social y política. Se fraguó entonces el movimiento feminista, una corriente de acción y pensamiento todavía sin nombre pero que fue el inicio del gran cambio que años más tarde culminaría en un nuevo sistema de relaciones entre los géneros. Pero el reconocimiento de las mujeres como sujetos activos de la Revolución apenas duró unos meses:

En 1789-1790, le féminisme et la Révolution n'apparaissent pas ouvertement comme conflictuels; une participation des femmes à la vie politique est bien accueillie souvent, voire sollicitée par les dirigeants en place. A partir de 1791, les choix constitutionnels et législatifs de la Révolution récusent le féminisme; la propagande de celui-ci s'en ressent et s'affaiblit, cependant que l'action politique des femmes tend à s'organiser plus solidement. Mais à l'automne 1793, l'interdiction des clubs de femmes vient leur retirer le droit même de s'organiser et, à fortiori, se trouve dénoncée toute action de type féministe (Devance, 1977: 342)1.

De aquellos años revolucionarios, conservamos retratos de muchas de las mujeres que encabezaron en Francia las nuevas propuestas de igualdad. Ciertamente, no pueden competir en número con las imágenes que se dedicaron a los prohombres de la Revolución, pero son lo suficientemente indicativas para advertirnos de su significativa presencia en los acontecimientos. Estos retratos tienen no solo un poder ilustrador, sino que hablan por sí mismos, a veces al margen de la propia historia escrita. A través de ellos nos situaremos en dos historias distintas, las de Théroigne de Méricourt y Olympe de Gouges, dos de las mujeres que junto con Madame Roland, Claire Lacombe y tantas otras, tomaron un papel activo en la Revolución. A causa de Théroigne -como veremos enseguida- hemos comenzado este escrito hablando de Delacroix. Sigamos con él.

En efecto, prosigamos: la Libertad de este pintor es sin duda el paradigma de lo que el imaginario de la Revolución
Francesa dejó en la colectividad, por mucho que no se pintara para ella, sino para la que tuvo lugar cuarenta años más tarde, en julio de 1830. En ese mismo año, Auguste Barbier había escrito lo que se considera la imagen literaria de la figura femenina del cuadro de Delacroix:

\section{C'est que la Liberté n'est pas une comtesse Du noble faubourg Saint-Germain, \\ [...] C'est une forte femme aux puissantes mamelles, À la voix rauque, aux durs appas, Qui, du brun sur la peau, du feu dans les prunelles, Agile et marchant à grands pas [...] (1830: 10-11)².}

Ágil y de paso rápido es la mujer que describe Barbier, como la que aparece en el cuadro; y también, como ella, de «pechos poderosos». Y por supuesto, como más adelante se insiste en el poema, hermosa; y desnuda, como parcialmente aparece en el lienzo. Aunque no podemos hacer una transcripción literal de los versos (con trasfondo satírico) a la pintura de Delacroix, lo cierto es que las dos figuras femeninas parecen hablar de una sola mujer. Este poema significó el reconocimiento para su autor, quien: «Como nuestro Zorrilla después de que leyó sus versos en la tumba de Larra, Barbier, que se acostó desconocido la víspera de publicar La Ralea, al otro día siguiente se levantó célebre» (Pardo, 1921, póstuma: 254). No era el caso del pintor, ya conocido por haber realizado, entre otros cuadros, La matanza de Quíos o Grecia expirando sobre las ruinas de Missolonghi, en el cual de nuevo una mujer representa a una patria en la que carece de derechos. En cualquier caso, La libertad guiando al pueblo es también la obra más popular del pintor. La mujer que allí retrata nos retrotrae a cuatro décadas atrás, cuando la revolucionaria Théroigne de Méricourt vivía en las calles de París su particular cruzada.

\section{II}

Théroigne; la nombramos en primer lugar porque enlaza (al igual que lo hiciera el poema de Barbier) con el cuadro de Delacroix. Es una idea común entre los historiadores que fue ella quien iluminó al pintor francés para su Libertad, la que le inspiró «para el personaje de la mujer que en primera línea avanza con gorro frigio y sostiene la bandera tricolor en 
medio de la batalla» (Regnier, 2015: 85). Parece en efecto que esta figura tiene tras de sí un rostro verdadero, el de Anne-Josèphe Terwagne (que tomó el nombre de Théroigne de Méricourt, mientras que la sociedad que califica por la apariencia la bautizó como «la bella liejense»). Es antológico el discurso que pronunció en la Société fraternelle des Minimes, el 25 de marzo de 1792:

Citoyennes, pourquoi n'entrerions nous pas en concurrence avec les hommes. Prétendent-ils eux seuls avoir des droits à la gloire; non, non... Et nous aussi nous voulons mériter une couronne civique, \& briguer l'honneur de mourrir (sic) pour une liberté qui nous est peut être plus chere qu'à eux, puisque les effets du despotisme s'appesantiffoient encore plus durement sur nous têtes que sur leurs [...] Ouvrons une liste d'Amazones Françoises; \& que toutes celles qui aiment véritablement leur Patrie, viennent s'y inscrire... (1792: 6)³.

De discursos como el anterior, se ha colegido un carácter belicoso antes que una reivindicación de los derechos de las mujeres, a nuestro juicio inapelable. Añadida esta faceta a un presunto pasado de libertinaje, la historia nos ha devuelto un personaje "furioso" antes que a una mujer comprometida. Para Roudinesco, definitivamente su historia se ha escrito de forma extemporánea y a partir de rasgos excéntricos:

Accusée de toutes les infamies, traitée de catin ou accouplée à toutes sortes d' 'amants imaginaires, elle voit naître sous ses yeux, au moment même où s'épanouit sa vie de liberté, la fantastique légende qui fera d'elle, pour la posterité, l'opposée de son personnage: une amazone libertine, sensuelle, assoiffée de meurtes et de faubourgs (Roudinescu, 2010: 52)4.

Se ha hablado demasiado, y en demasiados sentidos, sobre el presunto espíritu belicista de Théroigne, pero si atendemos al discurso "Aux 48 sections», tenemos que concluir una llamada a la cordura: «Citoyens arrêton[s]-nous et réfléchissons, ou nous sommes perdus. Le moment est enfin arrivé, où l'intérêt de tous veut que nous nous réuniss[i]ons, que nous fassions le sacrifice de nos haines et de nos passions pour le salut public ${ }^{5}$, (1793), además de su convencimiento del papel mediador de las mujeres.

Sus simpatías hacia los girondinos de Brissot frente a los montañeses de Robespierre hizo que su estrella se des- dibujara tras la paliza recibida por un grupo de mujeres simpatizantes de La Montaña, que la desnudó y golpeó, imagen recogida en una caricatura de la época y en la que se la representa con un gorro frigio. Tras este hecho, cayó en lo que Esquirol bautizó como un caso de lipemanía (término acuñado por él mismo y que se define como melancolía depresiva). Una breve noticia en la prensa del momento daba cuenta de este hecho que marcó el inicio de la caída de la revolucionaria. El tristemente célebre hospital de la Salpêtrière fue la última residencia de Théroigne y el lugar en que murió.

¿Cómo era realmente esta muchacha?; ¿o cómo la dibujaron? En 1792 Jean Fouquet le hace un retrato de perfil, grabado por Gilles-Louis Chrétien [1]. El papel lleva dos inscripciones, una en la parte superior, donde leemos: «M"le Théroigne», y otra inferior, que reza: «Dess. p. Fouquet gr. p. Chrétien inv. du physionotrace Cloître St Honoré à Paris en 1792». ${ }^{6}$ La técnica del physionotrace con la que se elaboró la imagen permitía una gran fidelidad a la hora del retrato, así que debemos pensar que tanto el rostro como el cabello y los vestidos que vemos en el grabado, eran los que correspondían realmente a esta revolucionaria, que buscaría seguramente transmitir una nueva imagen respecto a otras anteriores que la representaban con vestidos femeninos e incluso con algún signo de coquetería. Y es que aquí la joven aparece con los cabellos cortos para una chica de la época y con vestimenta masculina, algo absolutamente excepcional, aunque ya Mme du Barry (otra de las víctimas del Terror) en un retrato de 1767 de Drouais, aparecía vestida en homme. Estos gestos anteceden al de otras mujeres que adoptaron el hábito del varón (algunas para pintar, otras para poder acceder a determinados estudios, otras para afirmar una sexualidad contracorriente). En el caso de Théroigne, sus contemporáneos la vieron cada vez más a menudo ataviada a lo amazona, siendo "la única de las grandes agitadoras que convirtió su apariencia vestimentaria en un significante identitario» (Sazbón, 2007: 57).

Para hacer el perfil mediante la técnica mencionada, era imprescindible la presencia de la persona retratada, de modo que imaginamos a Théroigne en Saint Honoré posando, o mejor, «pasando su perfil» a través del fisionotrazo, «una modalidad que se debe tener como la gran aportación del grabado del siglo XVIII al género» (Vega, 2010: 273). Tal técnica consistía en trabajar a partir de la proyección de sombras de una máquina que «era en realidad una especie 


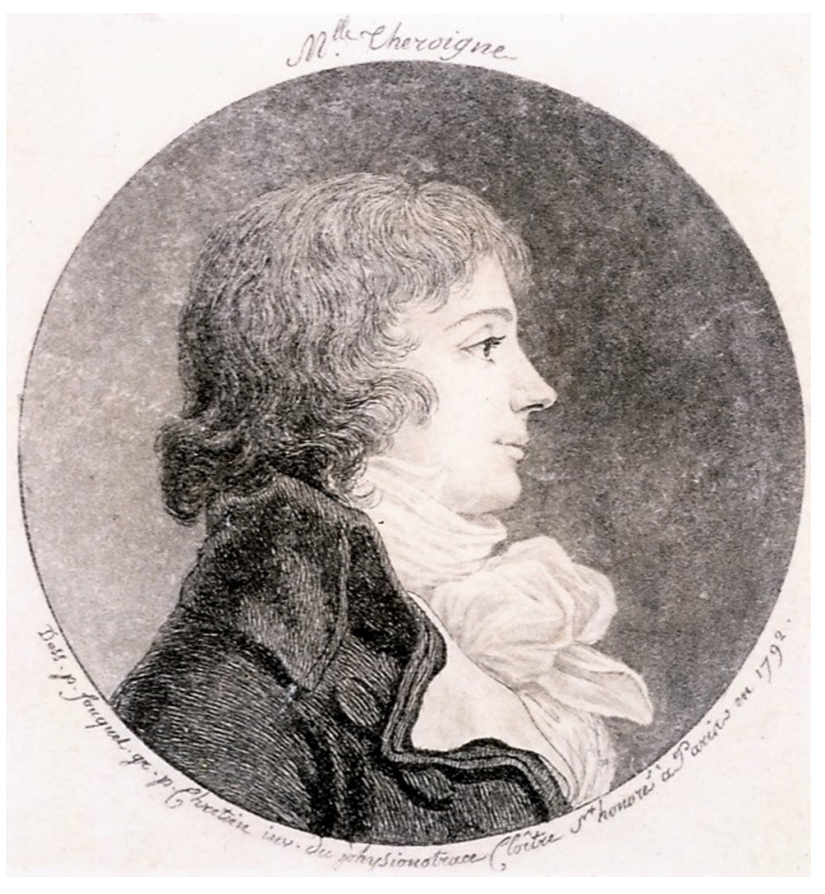

1. Théroigne de Méricourt, Retrato de Jean Fouquet, grabado de Gilles-Louis Chrétien, 1792

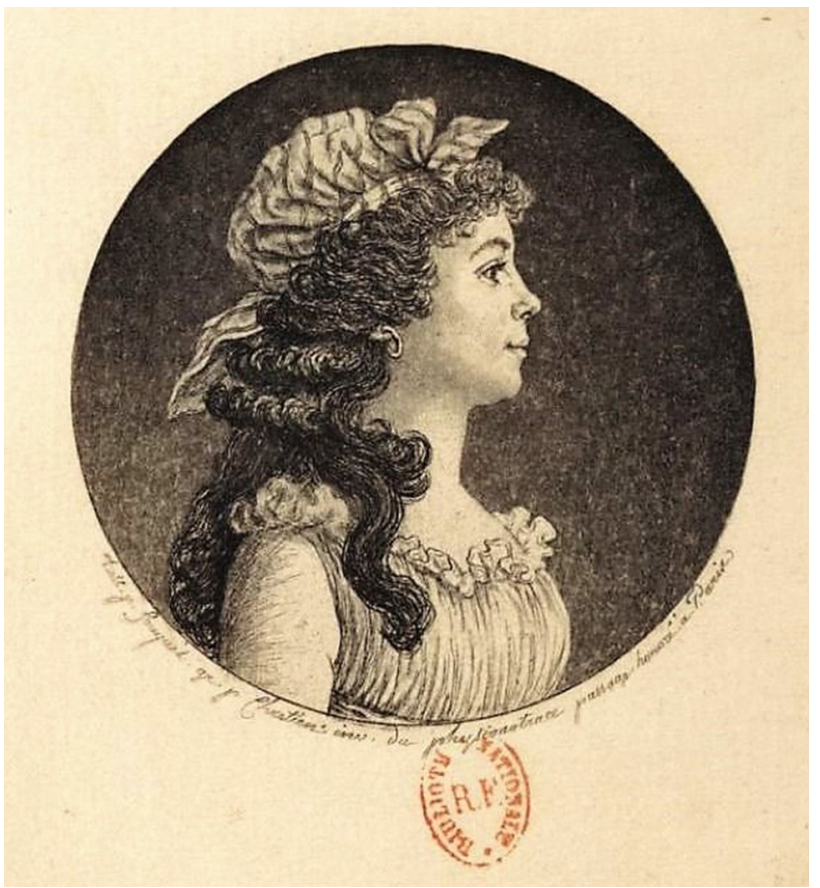

2. Théroigne de Méricourt, Retrato de Jean Fouquet. Grabado de Gilles-Louis Chrétien, anterior a 1792 de pantógrafo aplicado a la captación de la silueta, es decir, con ella a la vez que se recorría el perfil de la persona se dibujaba a tamaño natural sobre el papel» (Vega, 2010: 273). Fue inventada hacia 1785-1786 por Gilles-Louis Chrétien, tal como se reseña en el mismo retrato. Chrétien se asoció con Jean Fouquet, que realizaba los dibujos. Era una técnica barata y rápida, con la que se retrató a muchos de los revolucionarios franceses, entre otros a los antagonistas Robespierre y Brissot.

El aspecto general que nos devuelve el retrato es el de una joven con rasgos andróginos, dulce y sonriente, de característica nariz respingona que se ha tomado como referencia para tratar de identificar otras de sus imágenes. Retratos anteriores, concretamente en uno realizado con la misma técnica [2], confirman que en principio llevaba el cabello largo. Es esta la figura que Marcellin Pellet (1886: s/p) incluye en su libro como la de la revolucionaria, observando el parecido físico con otras representaciones de la época.

En otro retrato de autor no identificado conservado en la Biblioteca Nacional Francesa se la ve como una joven mundana, incluso portando un espejito [3]. Habría sido impreso en París hacia 1789 y pertenecido a la colección de Carl de Vinck. No es de extrañar que Théroigne quisiera nuevos retratos, que rompieran con estas imágenes, aunque en realidad todas ellas, en su suavidad compositiva, parecen contravenir la fama que, en aquellos días, le acompañaba. De todas maneras, sobre todo la imagen de 1792, nos confirma una mujer resuelta. Nada que ver con un presunto retrato atribuido a Antoine Vestier, fechado un año antes de la Revolución, en el que (si realmente es ella, cosa al parecer no muy probable) es vista como una joven indefensa y melancólica.

Cuando Théroigne llevaba casi veinticinco años muerta, en 1841, contamos con una nueva representación suya, que destacamos por ver la transformación que, en el imaginario postrevolucionario, experimenta su imagen. Se trata de un grabado de Denis Auguste Marie Raffet [4], conocido sobre todo por sus pinturas sobre las empresas napoleónicas. La imagina con dos pistolas al cinto y una espada, coronado el sombrero por un penacho, vestida como la mujer soldado que, en su día, habría encabezado la lucha. La misma a la que se refería Barthelemy para ilustrar su tercera jornada de la Revolución: «Sur ces groupes sans nom qui piétinaient l'arène / L'ardente Méricourt domine en souveraine» (1935: 79) 


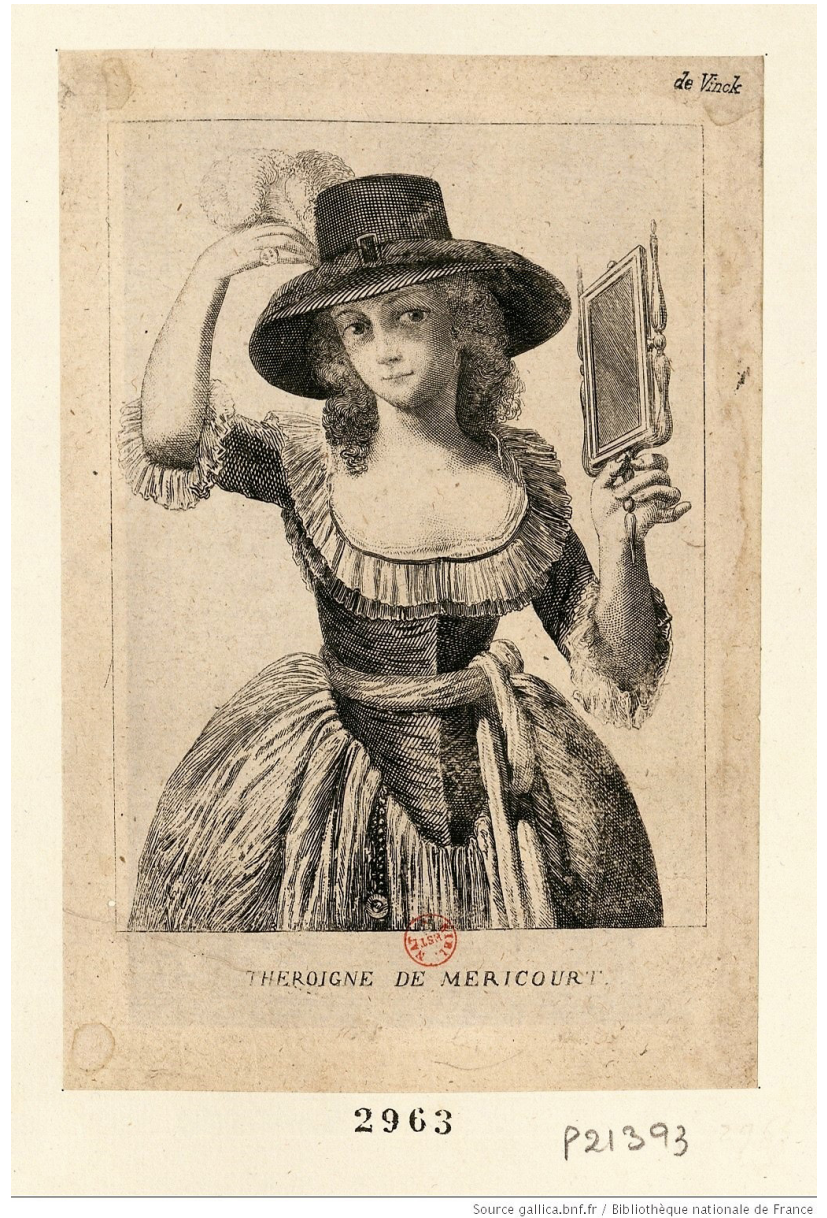

3. Retrato de Théroigne de Méricourt, h. 1789

Ya para siempre, la joven revolucionaria estará unida, en la leyenda, a un comportamiento fogoso y agresivo. Así la describe Michelet, en su controvertida versión de la revolucionaria: «lmpétueuse, charmante, terrible, Théroigne ne sentait nul obstacle... Elle avait eu des amours, mais alors elle n'en avait qu'un, celui-ci violent, mortel, que li coûta plus que la vie, L'amour de la Revolution» (1847: 296-297). ${ }^{8}$ Es a esa mujer en armas a la que se refiere Baudelaire en su poema Sisina de Las flores del mal:

Avez-vous vu Théroigne, amante du carnage,

Excitant à l'assaut un peuple sans souliers,

La joue et l'oeil en feu, jouant son personnage,

Et montant, sabre au poing, les royaux escaliers? ${ }^{9}$ (1861: 144)

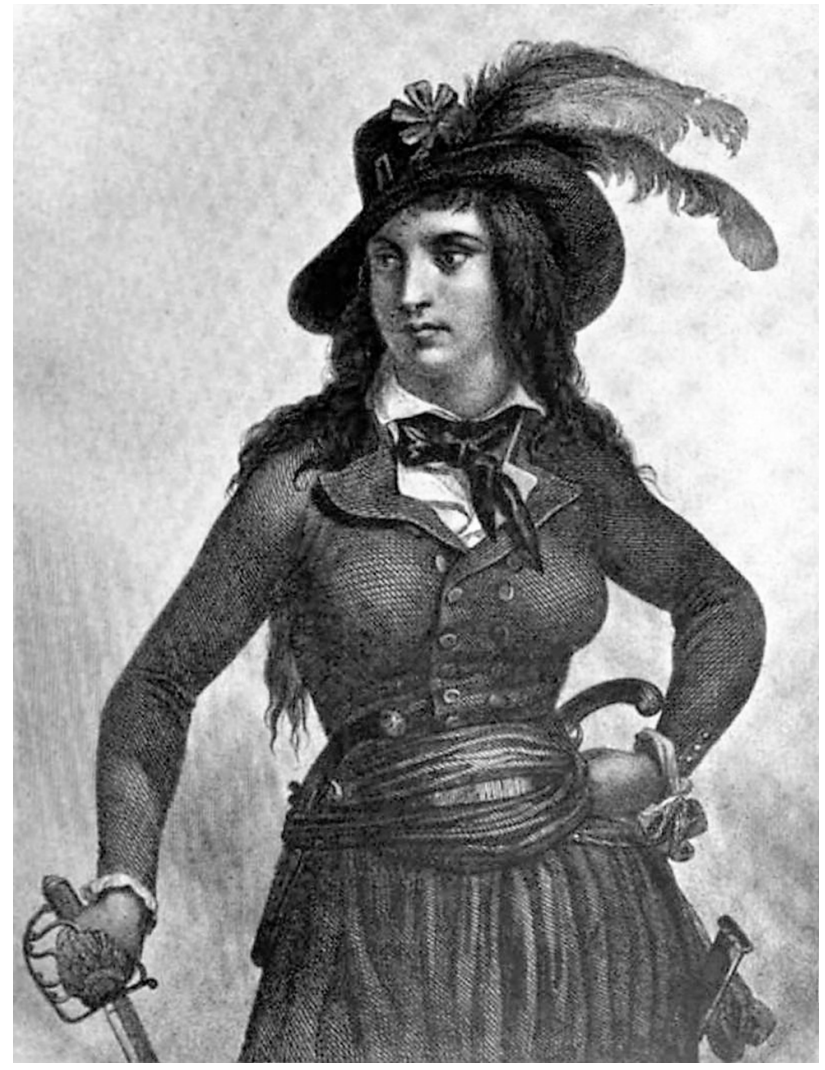

4. Théroigne de Méricourt retratada por Denis Auguste Marie Raffet, h. 1845

Poemas como este refuerzan la visión como furia de Théroigne, uniéndola a la famosas tricoteuses, que asistirían a las ejecuciones realizando labores de punto.

Pero poco o nada retiene de las imágenes comentadas el último retrato que conservamos de Méricourt [5]. Está incluido en el libro Des maladies mentales de Esquirol y nos revela a una mujer vencida, sin ningún interés hacia el lápiz que captaba su rostro: «L'ayant fait dessiner en 1816, elle s'est prêtée à cette opération; elle n'a paru attacher aucune importance à ce que faisait le dessinateur» ${ }^{10}$ (1838: 222). Es la imagen de una mujer vencida, que durante años se había infligido a sí misma los más duros maltratos:

Tous les jours, matin et soir, et plusieurs fois le jour, elle inonde son lit, ou mieux la paille de son lit, avec plusieurs seaux d'eau, se couche et se recouvre de son drap en été, 


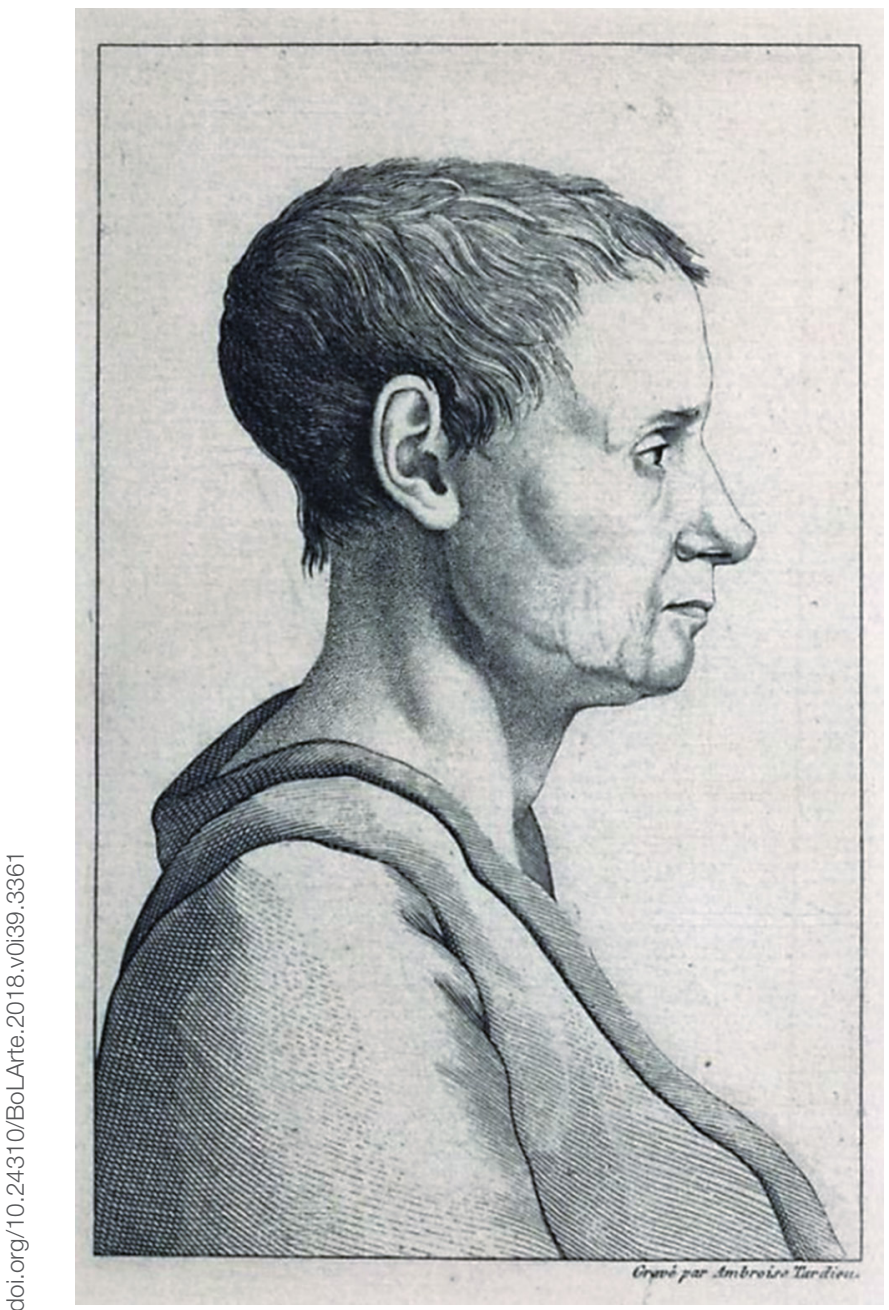

5. Théroigne de Méricourt en la Salpêtrière. Grabado de Ambroise Tardieu, tomado del dibujo de Georges Gabriel, 1816

et de son drap et de sa couverture en hiver. Ell se plaît à se promener nu-pieds dans sa cellule dallée en pierre et inondée d'eau. / Le froid rigoreux ne change rien à ce régime ... (Esquirol, 1838: 221) ${ }^{11}$.

Cuando llegó a la Salpêtrière, siempre según Esquirol, Theróigne hablaba de libertad, de Comités de salud pública, de revolucionarios, de moderados y realistas... todo ello lo contaba el que fuera su médico, el mismo que anuncia fríamente, antes de pasar a diseccionar su cuerpo: «Autopsie le 10 au matin», Autopsia a las 10 de la mañana (Esquirol, 1838: 222).
III

La última de las imágenes de Théroigne de Méricourt con vida nos la devuelve loca. La locura, seguramente, la salvó de la guillotina. Sin embargo, la cabal Olympe de Gouges no pudo escapar de ella, y pagó su compromiso revolucionario y su deseo de avenencia en la plaza de la Concordia, ese lugar que, durante el Terror, se convirtió en el epicentro de la ira del pueblo y de los que actuaron en su nombre. Olympe compartió espacio vital con la revolucionaria de Lieja, pero sus vidas y sus planteamientos políticos diferían notablemente. No tenemos noticias de su coincidencia en los distintos escenarios de la revolución.

Marie Gouze (la futura Olympe de Gouges) había nacido en el año 1748, catorce años antes que Théroigne. Conservamos de ella algunos retratos que, al igual que en el caso de la liejense, nos ayudan a aproximarnos a su figura y a su historia. Autora de la Declaración de los Derechos de la Mujer y la Ciudadana (necesariamente rescatada por el feminismo), Gouges fue además una defensora de los derechos de los negros, partidaria de la abolición de la pena de muerte, dramaturga y firme creyente -como se desprende de sus numerosos escritos- en el poder de la palabra como principio de acuerdo entre los seres humanos.

La primera representación de Olympe que debe llamarnos la atención es el grabado que aparece en su escrito Remarques patriotiques, de 1788 [6], pues contribuyó a que se difundiese la imagen de una mujer que de algún modo simpatizaba con la monarquía. La polémica, que ha llegado a nuestros días, de tales simpatías realistas, pretende quedar zanjada por Olivier Blanc: «Olympe de Gouges a tourné le dos au royalisme dès 1789 et elle a prouvé, dans ses écrits [...] qu'elle ne cessa jamais d'être une démocrate exemplaire attachée à la Déclaration des droits de l'Homme» $(2014 a)^{12}$. Si atendemos a la evolución de su pensamiento, puede decirse que Olympe de Gouges fue realista hasta el año de la revolución, cuando todavía veía posible la figura de unos reyes emblema de una nación, pero se sintió traicionada -como el resto de franceses- cuando vio las maniobras de Luis XVI enfrentándose a su pueblo y reclamando la ayuda de las potencias extranjeras. Por tanto, no ha de sorprendernos la portada de Remarques patriotiques, en la que Olympe aparece presentando su escrito a María Antonieta y a Louis XVI. El grabado fue encargado por la misma Olympe 
a Claude-Louis Desrais. Este artista, célebre por sus figurines para las Costumes français de la Galerie des modes, era una de las figuras más prestigiosas de su época y retrató a Olympe como una dama, con un característico pelo hueco y un vestido ajustado a la cintura.

Analicemos la imagen: Aparece perfectamente documentada. A la izquierda, firma del dibujante: Desrais inv. $\backslash A$ la derecha, firma del grabador: FruSsotte Sculp \Impression. Arriba, inscripción con el título: «LOUIS XVI À SON PEUPLE». Abajo: / «Vous la voyez cette Couronne de l'ambition, / je ne veux la Conserver que pour vous Deffendre / Et vous rendre heureux» ${ }^{13}$. En el grabado, el rey, con cetro, vestiduras con la flor de lys, collar de la orden del Santo Espíritu, está sentado sobre un carro «tiré par un coq (symbolisant l'éveil aux idées) et un mouton (la douceur et l'obéissance)»14 (Blanc, 2014b: 110). La reina está de pie a su lado, y en el plano inferior, junto a la propia Olympe, aparecen mendigos, niños, militares y religiosos. Junto a María Antonieta, un árbol sacudido por ella misma del que caen frutos que el pueblo recoge. Es a ella a quien más directamente interpela Olympe, de ella de quien espera comprensión y alimento. Para ambos (rey y reina) son estas palabras:

Le pain est cher; les travaux ne vont plus, \& les malhereux manquent de tout. [...] O Reine! Ô juste Monarque! Veuille I'humanité souffrance que mon récit vous touche en faveur des Infortunés dont je viens de vous tracer le deplorable sort! (1788: 15-16) ${ }^{15}$.

Esta obra, al ser de encargo, no nos da la medida de cómo ve el artista el conjunto de relaciones que en ella se expresan, sino la idea que tiene Olympe del papel de unos reyes en los que todavía ha depositado esperanzas y ante los cuales se pliega (no sin decirles, muy claramente, que no han sabido dar al pueblo ni siquiera el alimento).

Además de esta imagen, que al entrar dentro del campo de la alegoría no podemos considerar propiamente un retrato, Olivier Blanc (2014) señala la existencia de tres de ellos muy bien documentados: el primero una miniatura [7] ${ }^{16}$, que la misma autora «jugeait très ressemblante» y que «fut offerte au duc d'Orléans avec l'hommage des deux premiers tomes de ses CEuvres dramatiques» ${ }^{17}$ (2014: 50). Posiblemente, como el mismo autor indica, se trate de la imagen que reproduce Leopold Lacour en su libro Trois femmes de

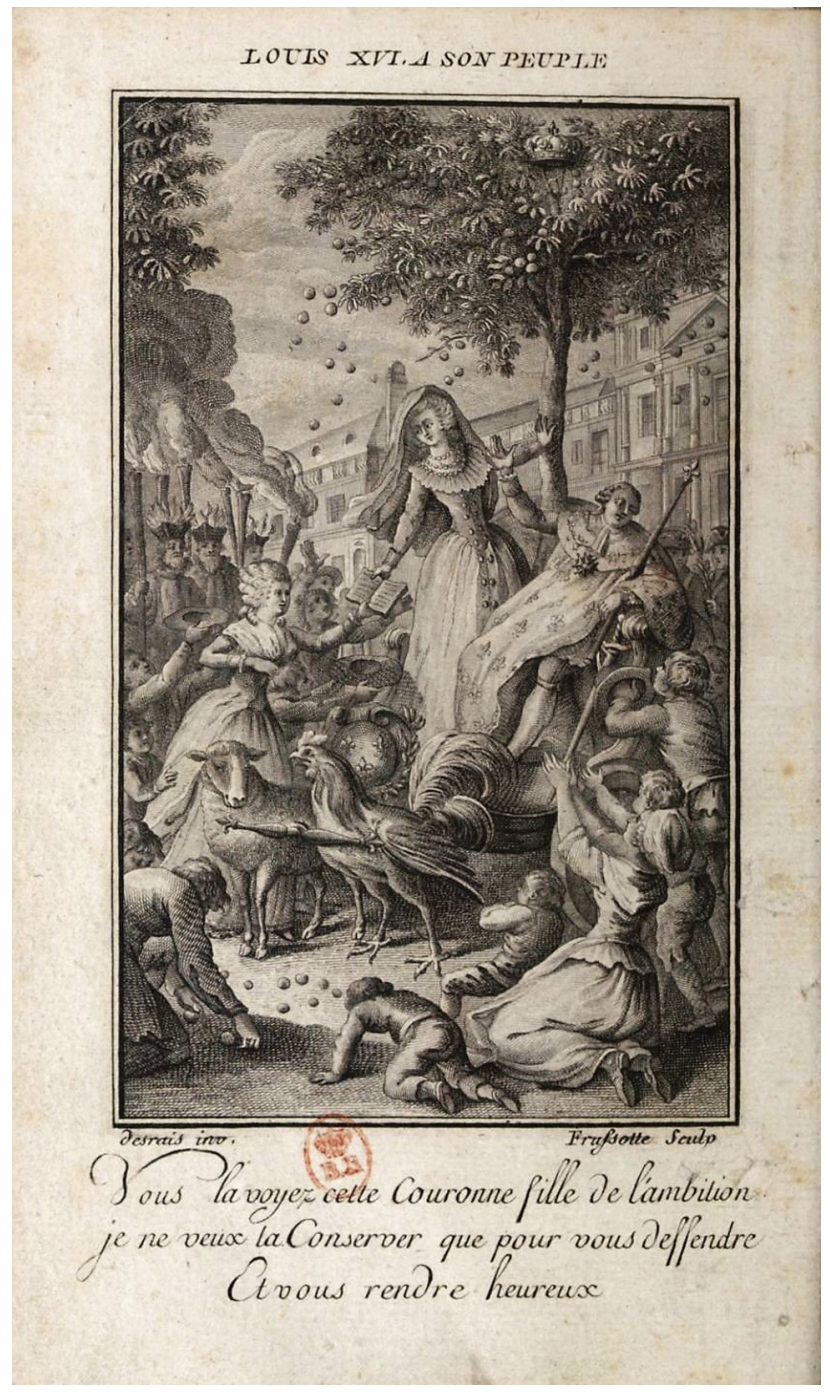

6. Olympe de Gouges en Remarques patriotiques. Dibujo de Desrais, grabado de Frussote, 1788 


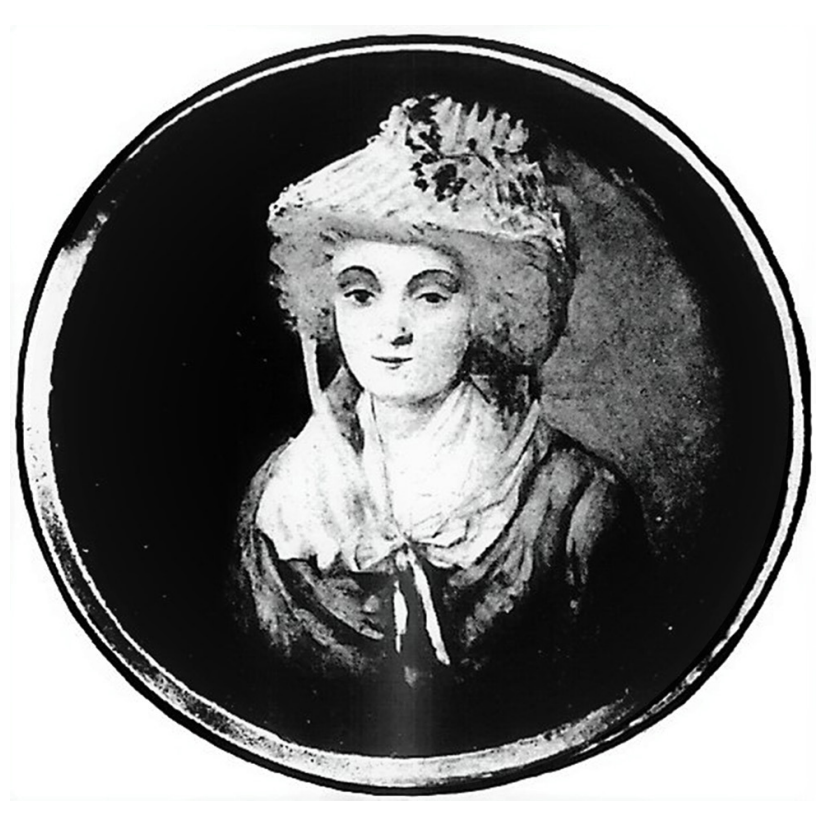

7. Miniatura de Olympe de Gouges, h. 1787-1788

la Révolution. Olympe de Gouges, Théroigne de Méricourt, Rose Lacombe (1900).

El segundo sería un dibujo a la mina de plomo realzado con acuarela. Está esbozado y posiblemente pueda ser una obra preparatoria para un óleo. Se encuentra en el Museo del Louvre [8]. En él, Olympe se encuentra sentada en un sillón Luis XV y sostiene un libro en una de sus manos. El tercer retrato es un pastel perteneciente a una colección particular [9], «rappelant la manière du portraitiste polonais Alexandre.Kucharski, actif à Paris dans les années 1780»18 (Blanc, 2014b: 51) y por tanto atribuido a este pintor, retratista oficial de María Antonieta cuando Elizabeth de Vigée-Lebrun abandonó París. Otras imágenes que algunas veces han sido interpretadas como retratos de Olympe no están confirmadas. Ejemplo de ello es la del Museo Carnavalet, en la que encontramos una mujer melancólica poco relacionada con las representaciones que sí sabemos son de su persona [10]. Este retrato, además, no reproduce el rostro redondeado y las cejas curvadas características de Olympe. Por el contrario, tiene el aire de ciertos frescos romanos.

¿Qué nos dicen los retratos confirmados como suyos? La variedad respecto a los de Théroige de Mericourt es menor. En los tres es representada como una dama, en uno de ellos con un libro en la mano, lo que permite situarla en el ámbito de la reflexión intelectual, cosa que sin duda sería de su agrado. Carente de la esmerada educación que ella hubiera deseado, ganó con su esfuerzo un lugar entre la dramaturgia de la época e incluso entre los escritores de la revolución. La historia y el feminismo la recuerdan sobre todo por Les droits de la femme, y su apartado de la Declaración de los derechos de la mujer y de la ciudadana, donde interpela directamente a los hombres, cuestionándoles su posicionamiento secular frente a las mujeres. Ellos, "supinamente ignorantes», habrían querido gobernar como déspotas "sur un sexe qui a reçu toutes les facultés intellectuelles» ${ }^{19}$ (Olympe de Gouges, 1971) y que sin embargo carece de los más elementales derechos: «Nul ne doit être inquiété pour ses opinions mêmes fondamentales, la femme a le droit de monter sur l'échafaud; elle doit avoir également celui de monter à la Tribune; pourvu que ses manifestations ne troublent pas l'ordre public établi par la Loi» ${ }^{20}$.

Esta obra la dedica a María Antonieta, hecho que viene a reavivar la polémica de la presunta adhesión al realismo de Olympe de Gouges, aunque estamos con Oliva Blanco cuando afirma que «la dedicatoria de Olimpia de Gouges a la Reina, más que como una adhesión a la monarquía quepa interpretarla como una declaración de sororidad» (2011: 227). Una mujer busca la interlocución de otra mujer que, necesariamente, debería aceptar la valía de su propio sexo.

En los retratos, decíamos, la escritora aparece como una dama, pero con distintos matices. En la miniatura nos encontramos con una mujer que hace valer el ornamento, sobre todo a partir del complejo tocado. En adelante, sin embargo, (y muy posiblemente de forma paralela a un buscado proceso de inmersión intelectual) la vemos con una apariencia más sobria. Si en el dibujo-acuarela en el que sostiene un libro ya se percibía una voluntad de ponderación, en el retrato atribuido a Alexandre Kucharski la simplicidad es máxima. Este pintor tenía el hábito, como recuerda Blanc (2014:51), de recomendar a las mujeres que posaban para él, llevar un pañuelo cruzado sobre el pecho para hacer que se concentrara la expresión sobre el rostro y no sobre un escote pronunciado. Esta manera de abordar a sus modelos sería del gusto de una Olympe cada vez más centrada en su labor de escritora y menos en el de la actriz que también fue. 


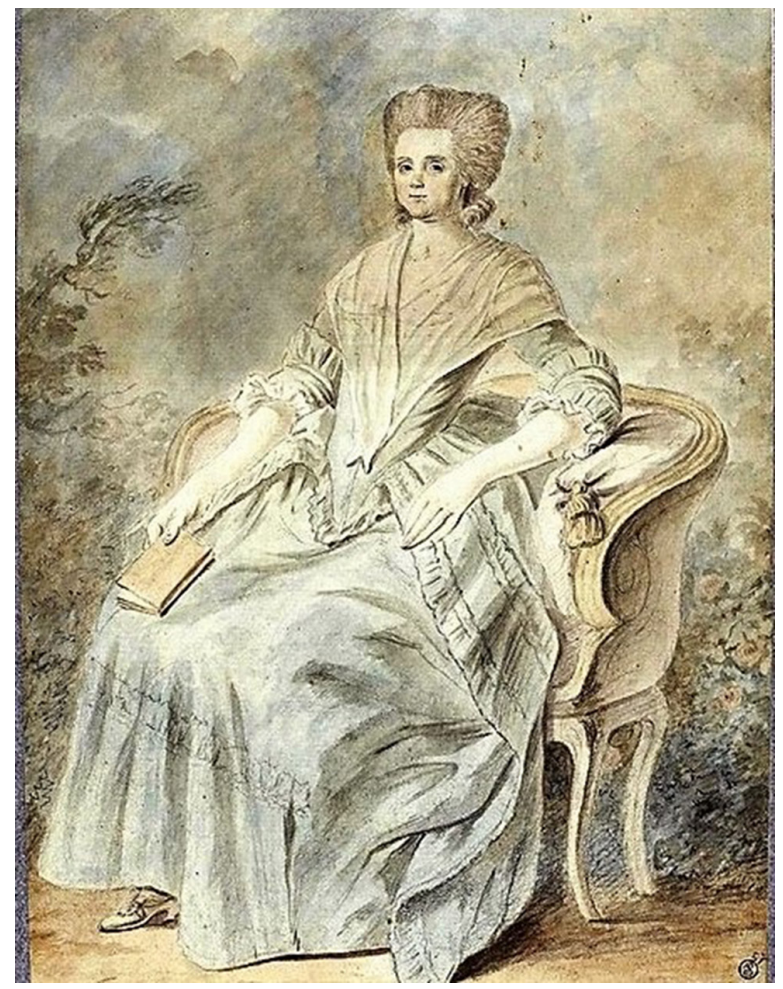

8. Olympe de Gouges en la obra inacabada de El Louvre, h. 1790-91

Olympe posó para Kucharki. También lo hizo María Antonieta, en el que quizá fuera su último retrato. Del mismo modo, cruzaba un pañuelo sobre su pecho. El comedimiento no le salvó de la guillotina. Tampoco Olympe escapó de ella. Había olvidado, según se dijo entonces, la discreción que convenía a su propio sexo. Su defensa del papel de las mujeres y su enfrentamiento a la Montaña acabaron con su vida. Apenas 20 días separaron la muerte de Olympe de Gouges y la de María Antonieta, dos destinos trágicos para dos mujeres que convivieron en el espacio y el tiempo, pero que solo tuvieron en común precisamente eso: su destino. En algún lugar se reunió con ellas, algunos años más tarde, Théroigne de Méricourt.

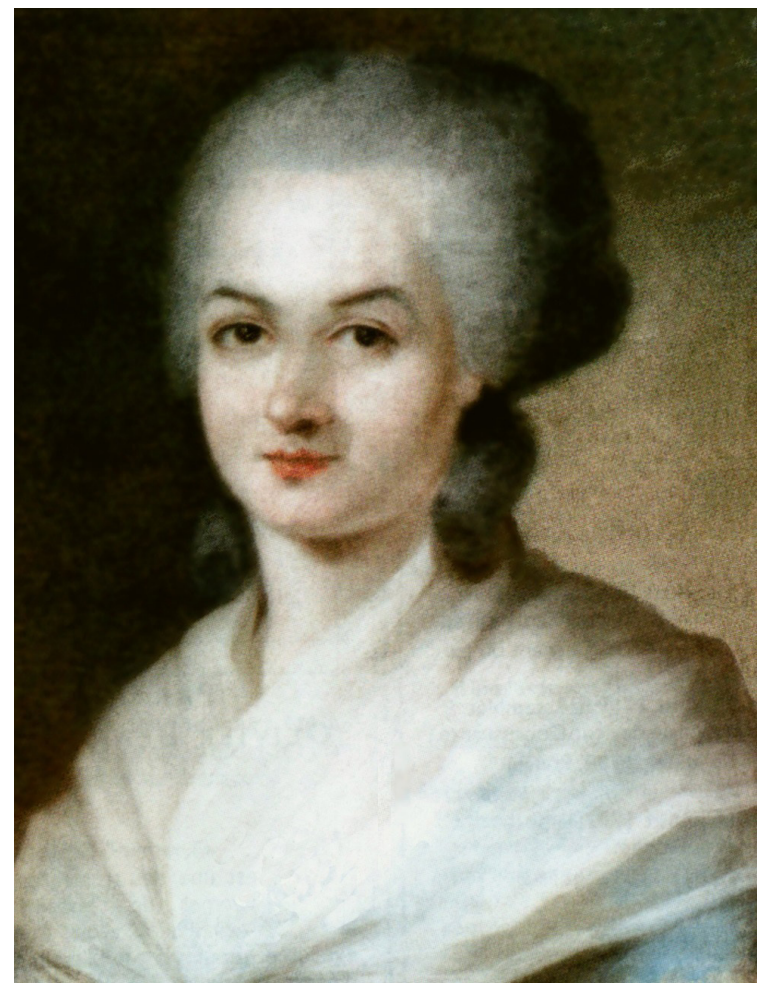

9. Retrato de Olympe de Gouges, atribuido a Alexandre Kucharski. Pastel

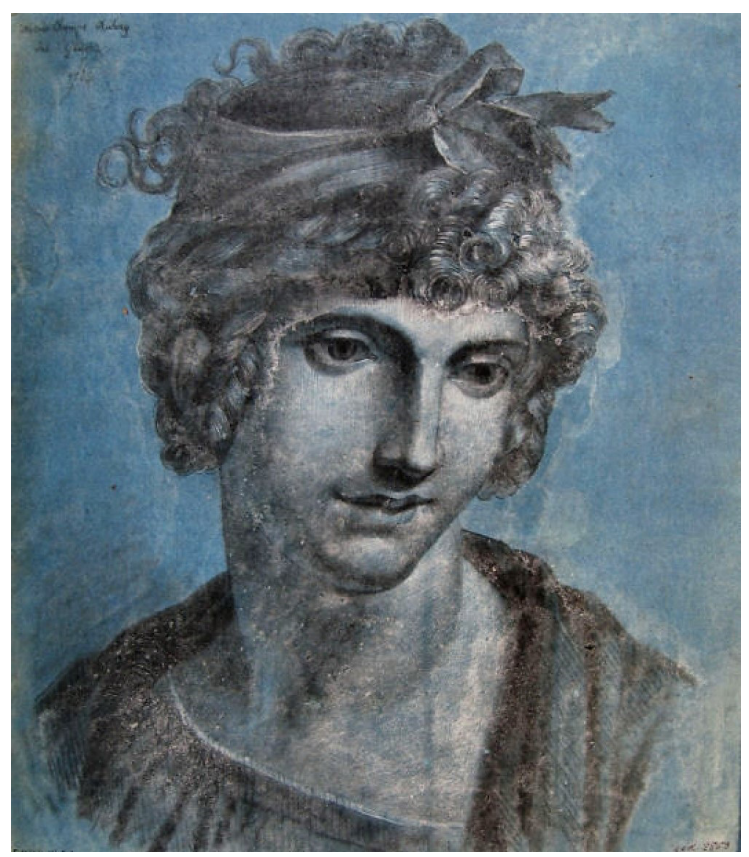

10. Improbable retrato de Olympe de Gouges. Carboncillo y gouache sobre papel, 1784 


\section{Notas}

1 En 1789-90, el feminismo y la Revolución no estaban abiertamente en conflicto; la participación de las mujeres en la vida política es a menudo bien acogida e incluso solicitada por los líderes del momento. A partir de 1791, las elecciones constitucionales y legislativas de la Revolución recusan el feminismo; la propaganda de este último se resiente y debilita, aunque la acción política de las mujeres tiende a organizarse más sólidamente. Pero en el otoño de 1793, la prohibición de los clubes de mujeres les quitó el derecho de organizarse y, a fortiori, se denunció toda acción de tipo feminista. [Todas las traducciones son propias].

2 La Libertad no es una condesa / Del noble barrio de Saint-Germain, [...] Es una mujer fuerte de poderosos pechos, / De voz ronca, de duros encantos, / Quien, morena su piel, sus pupilas de fuego, / Marcha ágilmente a zancadas [...].

3 Ciudadanas, ¿por qué no competir con los hombres? ¿pretenden tener ellos solos derecho a la gloria?, no, no...; Nosotras también merecemos una corona cívica y brillar con el honor de morir por una libertad que quizás nos sea más querida que a ellos, ya que los efectos del despotismo son incluso más severos sobre nuestras cabezas que sobre las suyas [...] Abramos una lista de Amazonas Francesas; y que todas aquellas que amen verdaderamente su patria, vengan a inscribirse...

4 Acusada de todas las infamias, tratada como una prostituta o emparejada con toda clase de amantes imaginarios, ella ve nacer ante sus ojos, en el mismo momento en que florece su vida hacia la libertad, la fantástica leyenda que hará de ella, para la posteridad, lo opuesto de su personaje: una amazona libertina, sensual, sedienta de sangre.

5 Ciudadanos, parémonos y reflexionemos o estamos perdidos. Ha llegado el momento en el que el interés de todos quiere que nos reunamos, que sacrifiquemos nuestros odios y nuestras pasiones a la salud pública.

6 Esto es: «Dibujado por Fouquet y grabado por Chrétien, inventor del physionotrace, Cloître St Honoré en París en 1792».

7 Sobre estos grupos sin nombre que pisoteaban la arena / La ardiente Méricourt domina soberana.

8 Impetuosa, hermosa, terrible, Theroigne no percibía obstáculo... Ella había tenido amores, pero entonces solo tenía uno, violento, mortal, que le cuesta más que la vida mortal, el amor por la Revolución.

9 ¿Habéis visto a Theroigne, amante de la carnicería, / incitando al asalto al pueblo descalzo, / Con las mejillas y los ojos de fuego, interpretando a su personaje, / y subiendo, sable en mano, las escaleras reales?

10 Habiéndola hecho dibujar en 1816, ella se ha prestado a esta operación; no parecía darle ninguna importancia a lo que hacía el dibujante.

11 Todos los días, mañana y tarde, y varias veces durante el día, inunda su cama, o mejor, la paja de su cama, con varios baldes de agua, se acuesta y en verano se cubre con su sábana, y con su sábana y su manta en invierno. Ella se complace en pasearse descalza en su celda pavimentada de piedra e inundada de agua. / El frío riguroso no cambia este régimen...

12 Olympe de Gouges le dio la espalda al realismo desde 1789 y ha probado, en sus escritos [...] que no cesó jamás de ser una demócrata ejemplar unida a la Declaración de los derechos del Hombre.

13 Luis XVI a su pueblo. Ved esta Corona de la ambición, / Yo no la quiero conservar más que para Defenderos. Y haceros feliz.

14 Tirado por un gallo (simbolizando el despertar a las ideas) y un cordero (el dulzor y la obediencia).

15 El pan es caro, el trabajo no va adelante, a los desafortunados les falta de todo [...] ¡Oh Reina! ¡Oh justo Monarca! ¡Quiera la humanidad sufriente que mi relato os conmueva en favor de los Infortunados de los que acabo de trazar su deplorable suerte!

16 La fecha es aproximada, y calculada a partir de la edición de los tomos I y || de sus CEuvres dramatiques. La datación de las imágenes 8 y 9 también es orientativa.

17 «Juzgaba muy parecido» y que «fue ofrecido al duque de Orleans como presente junto a los dos primeros tomos de sus CEuvres dramatiques».

18 Recordando el estilo del retratista polaco Alexandre Kucharski, activo en París en los años 1780.

19 Sobre un sexo que ha recibido todas las facultades intelectuales.

20 [...] Nadie debe ser hostigado por sus opiniones incluso fundamentales, la mujer tiene el derecho de subir al cadalso; debe tener igualmente el de subir a la tribuna; siempre que sus manifestaciones no perturben al orden público establecido por la Ley.

\section{Bibliografía}

BARBIER, Auguste (1830/1840), «La curée», Satires et poëmes, Société belge de librairie. Hauman et $C^{\circ}$, Bruselas.

BARTHELEMY (1835), Douze journées de la Revolution: poëmes, Pérrotin Editeur, París.

BAUDELAIRE, Charles (1861/2003), Charles Baudelaire. Obra poética completa. Texto bilingüe. Edición de Enrique López Castellón, Akal, Madrid.

BLANC, Olivier (2014a), «A propos du discours prononcé à Blois par Mme Najat Vallaud-Belkacem, ministre de l'Education nationale, le 10 octobre 2014». En <http://feministesentousgenres.blogs.nouvelobs.com/archive/2014/10/31/republicaine-feministe-antiraciste -olympe-de-gouges-devrait-546005.html> (fecha de consulta: 7/08/2017).

- (2014b), Olympe de Gouges. Des droits de la femme à la guillotine, Tallandier, París. 
BLANCO CORUJO, Oliva (2011), «Mi heroína favorita: Olimpia de Gouges», en BORJA, Margarita (ed.) Olimpia de Gouges o la pasión de existir, Universitat Jaume I, Castellón.

DEVANCE, Louis (1977), «Le féminisme pendant la Révolution française», Annales historiques de la Révolution française, n. ${ }^{\circ} 229,1977, \mathrm{pp}$. 341-376.

ESQUIROL, Jean-Étienne-Dominique (1838), Des maladies mentales considérées sous les rapports médical, hygiénique et médico-legal, tome premier, Meline, Cans et Compagnie. Librairie, Imprimirie Fonderie, Bruselas.

GOUGES, Olympe de (1788), Remarques patriotiques. Texto completo en francés en https://archive.org/stream/remarquespatriot00goug\#page/n1/mode/2up (fecha de consulta: 16/09/2017).

- (1791), Les droits de la femme. Texto disponible en http://gallica.bnf.fr/ark:/12148/bpt6k64848397 (fecha de consulta: 16/09/2017).

LACOUR, Léopold (1900), Trois femmes de la Révolution. Olympe de Gouges, Théroigne de Méricourt, Rose Lacombe, Librairie Plon, París. MICHELET, Jules (1847), Historie de la Révolution française, Chamerot, Libraire-Éditeur, París.

PARDO BAZÁN, Emilia (póstuma: 1921/2017), El lirismo en la poesía francesa, Red ediciones, Barcelona.

PELLET, Marcellin (1886), Étude historique et biographique sur Théroigne de Méricourt, Maison Quantin, París.

REGNIER, Nicole (2015), «iA las armas, amazonas!», en Théroigne de Méricourt, La furia: Proclamas y manifiestos de una revolucionaria caníbal, La Felguera editores, Madrid.

ROUDINESCO, Élisabeth (2010) (préf. Élisabeth Badinter), Théroigne de Méricourt: une femme mélancolique sous la Révolution, Albin Michel, coll. Bibliothèque de l'Évolution de l'humanité, París.

SAZBON, José (2007), «Figuras y aspectos del feminismo ilustrado», en Olympe de Gouges, Etta Palm, Théroigne de de Méricourt, Claire Lacombe. Cuatro mujeres de la Revolución francesa, Biblos, Buenos Aires.

THÉROIGNE DE MÉRICOURT (1972), Discours prononcé à la Société fraternelle des minimes, le 25 mars 1792, l'an quatrième de la liberté, par Mlle Théroigne, en présentant un drapeau aux citoyennes du faubourg S. Antoine. Fuente: gallica.bnf.fr / Bibliothèque Nationale de France.

- (1973), Aux 48 sections. Fuente: gallica.bnf.fr / Bibliothèque Nationale de France.

VEGA, Jesusa (2010), Ciencia, Arte e llusión en la España Ilustrada, Consejo Superior de Investigaciones Científicas, Madrid. 
